\title{
Charge transport orthogonality in all-polymer blend transistors, diodes, and solar cells
}

\author{
Simone Fabiano, S. Himmelberger, M. Drees, Z. Chen, R.M. Altamimi, A. Salleo, M.A. Loi
} and A. Facchetti

\section{Linköping University Post Print}

\section{Tweet}

N.B.: When citing this work, cite the original article.

Original Publication:

Simone Fabiano, S. Himmelberger, M. Drees, Z. Chen, R.M. Altamimi, A. Salleo, M.A. Loi and A. Facchetti, Charge transport orthogonality in all-polymer blend transistors, diodes, and solar cells, 2014, Advanced Energy Materials, (4), 6, 1301409.

http://dx.doi.org/10.1002/aenm.201301409

Copyright: Wiley-VCH Verlag http://www.wiley-vch.de/publish/en/

Postprint available at: Linköping University Electronic Press http://urn.kb.se/resolve?urn=urn:nbn:se:liu:diva-116393 
DOI: 10.1002/aenm.201301409

Article type: Communication

\section{Charge Transport Orthogonality in All-Polymer Blend Transistors, Diodes, and Solar} Cells

Simone Fabiano, Scott Himmelberger, Martin Drees, Zhihua Chen, Rashid M. Altamimi, Alberto Salleo,* Maria Antonietta Loi,* and Antonio Facchetti*

Dr. S. Fabiano, ${ }^{[+]}$Prof. M. A. Loi

Zernike Institute for Advanced Materials

University of Groningen

Nijenborgh 4, 9747 AG Groningen, The Netherlands

E-mail: m.a.loi@rug.nl

S. Himmelberger, Prof. A. Salleo

Department of Materials Science and Engineering

Stanford University

476 Lomita Mall, McCullough Building

Stanford, CA 94305, USA

E-mail: asalleo@stanford.edu

Dr. Z. Chen, Dr. M. Drees, Prof. A. Facchetti

Polyera Corporation

Skokie, Illinois 60077, USA

E-mail: afacchetti@polyera.com

Dr. R. M. Altamimi

Petrochemicals Research Institute

King Abdulaziz City for Science and Technology "http://www.kacst.edu.sa"

P.O. Box 6086, Riyadh 11442

Saudi Arabia

[+] Present address: Organic Electronics, Department of Science and Technology, Linköping University, SE-601 74 Norrköping, Sweden

Keywords: all-polymer blends; charge transports; field-effect transistors; hierarchical structures; organic solar cells

During the past two decades organic semiconductors have been investigated for both fundamental and technologically-driven studies, ${ }^{[1]}$ which led to emerging applications in organic light-emitting diodes (OLEDs), ${ }^{[2]}$ polymer solar cells (PSCs), ${ }^{[3]}$ and field-effect transistors (FETs). ${ }^{[4]}$ It has been demonstrated, particularly for field effect transistors, ${ }^{[5]}$ that 
one of the crucial parameters enabling efficient device operation is attaining proper molecular packing and orientation of the semiconducting (macro)molecules in the active layer so that optimized film texturing and morphology are achieved. Moreover, novel functions in organic opto-electronic devices stemmed from mixing different organic semiconductors to realize bulk heterojuctions. Obviously, understanding and controlling the morphological properties of these semiconducting blends, including materials miscibility, solid-state crystallinity, film domain size, hierarchical structures and molecular orientation is essential for achieving efficient device performance. ${ }^{[6,7]}$ However, due to their different operating principles, not all opto-electronic devices have the same requirements for the supra-molecular organization of the organic semiconductor films. In FETs, charges need to travel parallel to the dielectric layer within a few monolayers of the organic semiconductor in contact with the insulator. Thus charge transport is sensitive to in-plane film continuity and the $\pi-\pi$ overlap of the bidimensional molecular layers at such an interface. ${ }^{[8]}$ On the other hand, precise control of the molecular organization in three dimensions is fundamental for diode architectures where charge transport occurs perpendicular to the electrodes. In the case of bulk heterojunction (BHJ) polymer solar cells (PSCs), it is highly challenging to achieve an optimal phase separation between the donor and acceptor materials. For optimal PSC operation, a donor/acceptor bi-continuous interpenetrating network should be achieved, which increases the heterojunction interface area and enables vertical conductive channels with respect to the substrate, resulting in appropriate bulk charge carrier mobility and high power conversion efficiency (PCE). ${ }^{[9]}$

Polymer-polymer blends are some of the most challenging organic semiconductor systems because of their complex thermodinamics of mixing. ${ }^{[10]}$ Most of the polymer-polymer blendbased devices are fabricated by spin coating the two-component mixture. This process typically yields lateral domains exhibiting well-defined topographical structures which are far from equilibrium. ${ }^{[7,11]}$ The boundary conditions imposed by the presence of additional 
interfaces, such as the polymer/air and the polymer/substrate interfaces, affect the characteristic length scales over which local free energy minimization occurs. ${ }^{[10,12]}$ Generally, the coarse morphologies obtained in polymer-polymer blends are considered one of the major causes for their low power conversion efficiencies in all-polymer solar cells. Substrate surface treatment and solvent evaporation rate control have been used to regulate phase segregation in polymer-polymer films. ${ }^{[13]}$ However, despite two decades of intensive research, a comprehensive picture of the morphology-performance relationships for different polymer blend-based electronic devices remains elusive. ${ }^{[14]}$ Furthermore, very few studies have analyzed all-polymer blend morphology variations vis-à-vis transport characteristics in more than one type of opto-electronic device.

In this work we fabricated PSCs, single-carrier diodes, and bottom-gate FETs based on blends of regioregular poly(3-hexylthiophene) (P3HT) and poly\{[N,N'-bis(2-octyldodecyl)naphthalene-1,4,5,8-bis(dicarboximide)-2,6-diyl]-alt-5,5'-(2,2'-bithiophene) (P(NDI2ODT2)) and examined the photovoltaic performance and ambipolar transport properties (Figure 1a). Our results show that the thin film morphology, including the hierarchical structure, polymer aggregation, and phase separation of the P3HT:P(NDI2OD-T2) blend, tuned by a specific solvent/solvent mixture selection, can dramatically alter charge transport characteristics from a preferential in-plane to an out-of-plane direction. Specifically, we found that the polymer aggregation and phase separation of the all-polymer blend can be directed from self-stratified to laterally phase-separated in thin films, with the former resulting in high balanced ambipolar field-effect mobility $\left(\sim 3 \times 10^{-3} \mathrm{~cm}^{2} \mathrm{~V}^{-1} \mathrm{~s}^{-1}\right)$ but very poor diode transport efficiency and PSC efficiencies $(\sim 0.1 \%)$. On the other hand, suppressing the preferential segregation of one of the two polymers leads to 10x higher PCEs $(\sim 1.3 \%)$, greater vertical charge transport, but 10x lower mobilities in a field effect transistor configuration $\left(\sim 3 \times 10^{-4}\right.$ $\left.\mathrm{cm}^{2} \mathrm{~V}^{-1} \mathrm{~s}^{-1}\right)$. Atomic force microscopy (AFM) and depth resolved X-ray photoemission 
spectroscopy (XPS) are used to rationalize the morphology variations and correlate them to the device performance.

BHJ solar cells, single-carrier diodes, and bottom-gate bottom-contact FETs (see Figure 1b-e) were fabricated using blends of the n-type polymer P(NDI2OD-T2) and the p-type polymer P3HT (Figure 1a). The evolution of the $J-V$ characteristics of three representative P3HT:P(NDI2OD-T2) solar cells prepared from different solvents is shown in Figure 2a and the crucial parameters are summarized in Table 1. Note that here to test the effect of the solvent we refer to a weight ratio of 1:1 (w/w) P3HT:P(NDI2OD-T2), although devices with a slight excess of P(NDI2OD-T2) were found to perform slightly better than the $1: 1$ blends. $^{[15]}$ BHJ solar cells processed from dichlorobenzene (DCB) exhibit high fill factors (nearly 60\%), but power conversion efficiencies of only $\sim 0.1 \%$, mainly limited by a very small short-circuit current of only $0.30 \mathrm{~mA} \mathrm{~cm}$. The low PCE and high fill factor are typical of a hierarchical phase separation as in a bilayer-like film. In this kind of device only a narrow layer near the planar heterojunction is involved in the exciton separation due to the limited exciton diffusion length, ${ }^{[16]}$ strongly limiting the device performance. ${ }^{[17]}$ To further understand vertical charge transport, electron-only and hole-only diodes devices were also fabricated using this solvent (see details in the Experimental Section). The zero-field mobilities extracted from the spacecharge limited current (SCLC)-voltage characteristics (Fig. S1) are $1.3 \times 10^{-4} \mathrm{~cm}^{2} \mathrm{~V}^{-1} \mathrm{~s}^{-1}$ for electrons and $0.4 \times 10^{-4} \mathrm{~cm}^{2} \mathrm{~V}^{-1} \mathrm{~s}^{-1}$ for holes. However, the use of xylene as the blend processing solvent results in a marked improvement of $J_{\mathrm{sc}}\left(1.02 \mathrm{~mA} \mathrm{~cm}^{-2}\right)$ while the fill factor and the open-circuit voltage remain unaffected, giving a PCE of nearly $0.3 \%$. These results are consistent with a more efficient lateral phase separation with respect to the self-stratified one, as demonstrated by the XPS and AFM analysis (vide infra). The best performance for this polymer-polymer blend, with a PCE of $1.31 \%$, was obtained when xylene and chloronaphtalene $(\mathrm{CN})$ were used in a binary-solvent mixture $(1: 1 \mathrm{v} / \mathrm{v})$. Recently it was found that $\mathrm{CN}$ suppresses the pre-aggregation of $\mathrm{P}(\mathrm{NDI} 2 \mathrm{OD}-\mathrm{T} 2)$ in solution, ${ }^{[18]}$ thus improving the 
solar cell performance mainly by a more efficient photogeneration of free charge carriers in the film bulk. ${ }^{[19]}$ Indeed, because light-induced excitons in BHJ-PSCs usually have short exciton diffusion lengths of only a few nanometers (typically less than $10 \mathrm{~nm}$ for several organic semiconductors ${ }^{[16]}$, a fine donor/acceptor phase separation results in efficient exciton dissociation. The improved vertical charge transport for the film processed from the xylene:CN mixture is corroborated by a two/ten fold increase in space-charge limited current mobilities $\left(\mu_{\mathrm{e}}=2.2 \times 10^{-4} \mathrm{~cm}^{2} \mathrm{~V}^{-1} \mathrm{~s}^{-1}\right.$ and $\left.\mu_{\mathrm{h}}=3.4 \times 10^{-4} \mathrm{~cm}^{2} \mathrm{~V}^{-1} \mathrm{~s}^{-1}\right)$. The external quantum efficiency (EQE) curves of the three types of PSC devices mentioned above are shown in Figure 2b. The EQE spectra show a broad response in the wavelength range from $400 \mathrm{~nm}$ to $850 \mathrm{~nm}$, which evidences the contribution of both P(NDI2OD-T2) $\left(\lambda_{\max }=400 \mathrm{~nm}\right.$ and 700 $\mathrm{nm})$ and P3HT $\left(\lambda_{\max }=550 \mathrm{~nm}\right)$ absorption. From the EQE spectra and from previously reported time resolved photoluminescence measurements, ${ }^{[20]}$ photons absorbed in both polymers ultimately contribute to the photocurrent.

Bottom-gate, bottom-contact field-effect transistors were also fabricated to examine the effect of the considerable morphology variation in a very different device geometry. In order to prevent electron-trapping at the dielectric-semiconductor interface, the hydroxyl groups on the dielectric surface were passivated with hexamethyldisilazane (HMDS). It is worthy to note that $\mathrm{P} 3 \mathrm{HT}$ and $\mathrm{P}(\mathrm{NDI} 2 \mathrm{OD}-\mathrm{T} 2)$ show similar surface energies (25.8 and $23.7 \mathrm{~mJ} \mathrm{~m} \mathrm{~m}^{-2}$, respectively $)^{[21]}$ thus, we do not expect any significant selective surface-driven wetting at such an interface. Indeed, a close inspection at the film blend morphology on $\mathrm{Si} / \mathrm{SiO}_{2}$ (surface energy $\left.=61.4 \mathrm{~mJ} \mathrm{~m}^{-2}\right)^{[22]}$ and $\mathrm{Si} / \mathrm{SiO}_{2}$-HMDS-treated $\left(43.6 \mathrm{~mJ} \mathrm{~m}^{-2}\right)^{[22]}$ substrates shows no significant differences (see Supporting Information Figure S2). As a consequence, our P3HT:P(NDI2OD-T2) transistors are an ideal platform to gain insights into the effect of hierarchical phase separation on the bi-dimensional charge transport.

Figure 2c,d shows the FET transfer characteristics of P3HT:P(NDI2OD-T2) blends processed from the three different solvents, for both p-channel $\left(\mathrm{V}_{\mathrm{D}}=-50 \mathrm{~V}\right)$ and $\mathrm{n}$-channel 
$\left(V_{D}=50 \mathrm{~V}\right)$ operations. The DCB-coated FETs typically exhibit balanced hole and electron transport characteristics with $\mu_{\mathrm{e}}=3.1 \times 10^{-3} \mathrm{~cm}^{2} \mathrm{~V}^{-1} \mathrm{~s}^{-1}, \mu_{\mathrm{h}}=2.9 \times 10^{-3} \mathrm{~cm}^{2} \mathrm{~V}^{-1} \mathrm{~s}^{-1}$ and an on/off current ratio $>10^{3}$. Note that typically mixing organic semiconductors strongly affects FET charge transport characteristics versus those of the single component-based devices. ${ }^{[23]}$ However, the electron and hole mobilities for FET devices with the P3HT:P(NDI2OD-T2) blend processed from DCB were found to be similar to those of the single polymer transistors. ${ }^{[20]}$ In this case indeed, the immiscibility of the two components (polymers) promotes the formation of stratified percolation pathways parallel to the dielectric/semiconductor interface, thereby affording a blend morphology enabling the efficient transport of both charge carriers. This result corroborates with the very low PCE (< $0.1 \%$ ) observed for the corresponding solar cells (see Table 1 for comparing solar cell and FET performances). On the other hand, when FETs are processed from xylene, both hole and electron mobilities are slightly reduced to typical values of $1.8 \times 10^{-3} \mathrm{~cm}^{2} \mathrm{~V}^{-1} \mathrm{~s}^{-1}$ and $1.4 \times$ $10^{-3} \mathrm{~cm}^{2} \mathrm{~V}^{-1} \mathrm{~s}^{-1}$, respectively. The lower ambipolar mobilities may be attributed to the formation of an interpenetrating network of well-crystallized P3HT nanofibers embedded into the $\mathrm{P}(\mathrm{NDI} 2 \mathrm{OD}-\mathrm{T} 2)$ phase, a result reflecting the enhanced PCE observed for the corresponding solar cells $(0.3 \%)$. Indeed, P3HT is known to self-organize in crystalline aggregates with improved mobility when processed from poor solvents such as xylene ${ }^{[24]}$ and this may also be the reason for the larger FET mobility for holes than electrons for blends processed from xylene. When $\mathrm{CN}$ is used as a co-solvent of xylene, the number of percolating pathways between source and drain electrodes sharply decreases, resulting in a 10x reduction in mobility for both holes and electrons and a reduced on/off current ratio $(\sim 10)$. The marked worsening of the transistor performances with respect to the DCB- and xylene-coated blends agrees very well with the PCE measurements previously discussed, implying a fine bulkheterojunction intermixing and/or the formation of primarily single-component domains extending perpendicular to the substrate surface. 
X-ray Photoelectron Spectroscopy (XPS) and Grazing Incidence Wide Angle X-Ray Scattering (GIWAXS) were performed on the blend films cast from the different solvents in order to determine the concentration profile of P3HT and P(NDI2OD-T2) throughout the film thickness and to study the molecular packing of the blend films, respectively. The substrate used for these measurements was $\mathrm{Si} / \mathrm{SiO}_{2}$-HMDS-treated. Note that the surface energy of $\mathrm{Si} / \mathrm{SiO}_{2}$-HMDS-treated $\left(43.6 \mathrm{~mJ} \mathrm{~m}^{-2}\right)^{[22]}$ compares favourably with that of PEDOT:PSS (47.5 $\left.\mathrm{mJ} \mathrm{m}^{-2}\right)^{[25]}$ which was used instead as an interlayer in the BHJ-PSCs. Because of the similar surface energy and roughness of these substrates, and considering that P3HT and P(NDI2ODT2) show similar surface energies (25.8 and $23.7 \mathrm{~mJ} \mathrm{~m}^{-2}$, respectively), ${ }^{[21]}$ we expect that the substrate should minimally affect the blend film morphology and microstructural order. The elemental composition was monitored as a function of the film depth until the silicon and oxygen signals increased sharply, indicating that the $\mathrm{Si} / \mathrm{SiO}_{2}$ substrate surface was reached (Figure 3). Since nitrogen is only present in P(NDI2OD-T2), it can thus be used as an indicator of the vertical composition of the films. Our XPS results indicate a marked difference in the concentration profiles between the blends processed from the different solvents (Figure 3a-c, see details in the Experimental Section). Films cast from DCB show a significantly higher concentration of $\mathrm{P}(\mathrm{NDI} 2 \mathrm{OD}-\mathrm{T} 2)$ at the top of the film relatively to the bottom interface (Figure 3a), while films cast from xylene show a slight concentration gradient with more P(NDI2OD-T2) near the top of the film surface (Figure 3b). On the other hand, films cast from a mixture of xylene: $\mathrm{CN}$ display a relatively uniform elemental distribution throughout the film (Figure 3c), indicating a well-mixed morphology. These differences in concentration profiles are in agreement with topological features observed by AFM (Figure 3d-f), TEM (Figure S4a), and SEM (Figure S4b). Although these techniques are not sensitive to the bulk phase morphology, they further elucidate the difference in phase separation at the surface between the three blends. A close inspection of the surface topography of the films cast from DCB reveals typical ribbon-like features having widths on 
the order of tens of nanometers (Figures 3d, S3 and S4). These features are consistent with the column lengths extracted from X-ray diffraction and AFM characterization of the pristine $\mathrm{P}(\mathrm{NDI} 2 \mathrm{OD}-\mathrm{T} 2)$ layer, suggesting a mesoscale phase separation with hierarchical blend morphology having a P(NDI2OD-T2) layer on top. ${ }^{[26]}$ GIWAXS diffraction peaks arising from both P3HT and P(NDI2OD-T2) are visible in all three blends (Figure S5). Films deposited from DCB and xylene both yield very similar diffraction patterns with strong scattering originating from the P3HT and P(NDI2OD-T2) alkyl stacking along the $q_{\mathrm{z}}$ and $q_{\mathrm{xy}}$ axes, respectively. This result indicates that $\mathrm{P} 3 \mathrm{HT}$ and $\mathrm{P}(\mathrm{NDI} 2 \mathrm{OD}-\mathrm{T} 2)$ in these films are stacking edge-on and face-on, respectively relative to the substrate. This is not unexpected for films which are largely phase separated, as these are the orientations typically observed in the neat films of these two polymers. On the other hand, films cast from xylene:CN show a more isotropic distribution of crystallites, indicated by the diffraction spots being broadened into rings (Figure S6). This is in agreement with our other experimental results suggesting a finer mixing of the two components in the film cast from xylene:CN. By using the Scherrer equation, we can estimate the coherence lengths of P3HT and P(NDI2OD-T2) in the alkyl stacking direction for each film. Films deposited from DCB show coherence lengths of 9.8 $\mathrm{nm}$ and $7.2 \mathrm{~nm}$ for P3HT and P(NDI2OD-T2), respectively, while those from xylene are similar (7.5 and $7.3 \mathrm{~nm}$, respectively). On the other hand xylene:CN processed films yield more ordered crystalline domains for both polymers with coherence lengths of $12.3 \mathrm{~nm}$ and 16.1 nm for P3HT and P(NDI2OD-T2), respectively. These data indicate that enhanced order of both polymer domains in the blend in combination with proper mixing is important to improve the PSC performance.

Vertically phase-separated structures have been observed for several spin-coated polymer blends upon solvent evaporation. ${ }^{[27]}$ In the present case, such vertical phase separation featuring a P(NDI2OD-T2)-rich top layer and a bottom interface mostly composed of P3HT would explain the low PCEs and SCL mobilities observed in the devices, which basically 
have a bilayer-like semiconductor structure (Figure 4). At the same time, bilayer percolating pathways parallel to the substrate support the good ambipolar transport observed for the DCBcoated FETs, showing that the high mobility of $\mathrm{P}(\mathrm{NDI} 2 \mathrm{OD}-\mathrm{T} 2)$ and $\mathrm{P} 3 \mathrm{HT}$ are indeed preserved upon blending. In particular, holes can be injected and travel in the P3HT-rich domains at the dielectric interface while electrons are injected into the P(NDI2OD-T2)-rich phase and travel at the P3HT:P(NDI2OD-T2) interface. Crystalline and continuous bidimensional conductive channels with respect to the substrate have been demonstrated by mixing polymer semiconductors with high-mobility small molecules, or using small molecules only, yielding ambipolar transistors. ${ }^{[28]}$

The use of xylene as a solvent results instead in strongly phase separated domains characterized by a network of poorly interconnected islands of P3HT (Figure 3e), in agreement with previous observations. ${ }^{[15,19]}$ Furthermore, addition of $\mathrm{CN}$ to the xylene solution has a strong effect on the nanoscale morphology of the polymeric films (Figure 3f), which results in more homogeneous films characterized by the lack of pronounced domain structure. This homogeneously intermixed blend morphology is consistent with increased PCEs and SCL mobilities as well as supporting the conclusions that the drop in field-effect mobility is due to the P3HT:P(NDI2OD-T2) mixture becoming homogeneous (Figure 4).

In summary, we have shown that control of the polymer aggregation and phase separation of an all-polymer blend can be used to effectively tune preferential charge transport within the blend from an in-plane to an out-of-plane direction. By depositing P3HT:P(NDI2OD-T2) films from different solvents, the degree of phase separation and film morphology of the two components can be varied significantly. Efficient polymer solar cells and diode transport are obtained by inducing laterally phase-separated blends, whereas self-stratified films result in high balanced ambipolar field effect mobility. Thus, the simultaneous control of several properties such as polymer crystallinity, domain size, materials miscibility, hierarchical 
structures and molecular orientation is a challenging but viable route toward further improvement of all-polymer device performance.

\section{Experimental Section}

Materials and Device fabrication: Photovoltaic devices were fabricated by using an ITO/PEDOT:PSS/P3HT:P(NDI2OD-T2)/LiF/Al architecture, with a PEDOT:PSS (poly(3,4ethylene dioxythiophene):poly(styrene sulfonate))-coated indium tin oxide (ITO) layer used as the transparent electrode. Pre-patterned ITO glass substrates were first cleaned in an ultrasonic bath using acetone and isopropanol and then treated with UV-ozone (20 min) prior to deposition of a 50-nm-thick PEDOT:PSS layer. PEDOT:PSS (Clevios P VP Al 4083) was spin-coated from aqueous dispersion at $2000 \mathrm{rpm}$ and dried at $140{ }^{\circ} \mathrm{C}$ for $10 \mathrm{~min}$ in ambient conditions. The substrates were then transferred to a nitrogen filled glovebox for active layer deposition. Highly regioregular P3HT was purchased from Sigma Aldrich (Plexcore OS 2100, regioregularity $>98 \%, \mathrm{M}_{\mathrm{n}}=54-75 \mathrm{~kg} \mathrm{~mol}^{-1}$, polydispersity $<2.5$ ), blended with P(NDI2ODT2) (ActivInk N2200, supplied by Polyera Corporation) and stirred overnight in a hot solution. The polymer blends were spin-coated from DCB, xylene and xylene:CN at $1500 \mathrm{rpm}$ with a weight ratio of $1: 1\left(10 \mathrm{mg} \mathrm{mL}^{-1}\right)$, following a routine that was reported earlier. Once the active layer has been deposited, the devices were completed by evaporation of $1 \mathrm{~nm}$ of $\mathrm{LiF}$, covered by a $100 \mathrm{~nm}$ aluminium top electrode via thermal evaporation through a shadow mask. The active area of the solar cells was $4 \mathrm{~mm}^{2}$.

Bottom-gate/bottom-contact field-effect transistors were fabricated by spin-coating the polymer blend solutions on heavily doped p-type Si substrates with a 200-nm-thick thermally grown $\mathrm{SiO}_{2}$ layer as the gate dielectric $\left(\mathrm{C}_{\mathrm{d}}=17 \mathrm{nF} \mathrm{cm}{ }^{-2}\right)$. Interdigitated source and drain electrodes were defined lithographically and consist of $10 \mathrm{~nm}$ of Ti and $30 \mathrm{~nm}$ of Au. All the substrates were cleaned stepwise in acetone and isopropanol in an ultrasonic bath and then treated with UV-ozone for $20 \mathrm{~min}$. Before the deposition of the P3HT:P(NDI2OD-T2) blend, the silicon oxide substrates were modified with a hexamethyldisilazane (HMDS) self- 
assembled monolayer. The active layer was then spin-coated following the recipe used for solar cell fabrication. Both the HMDS treatment and polymer blend deposition were carried out in a controlled-atmosphere glovebox filled with $\mathrm{N}_{2}$. The FETs were then transferred to a vacuum probe station and left under vacuum conditions overnight to remove residual contaminants from the active layer.

Space-charge limited current (SCLC) devices were fabricated by spin-coating the polymer blend solutions onto ITO substrates. For hole-only devices $8 \mathrm{~nm} \mathrm{MoO} 3$ were evaporated as the interface between ITO and the polymer blend layer and $8 \mathrm{~nm} \mathrm{MoO}$ followed by $120 \mathrm{~nm} \mathrm{Ag}$ were evaporated as top electrode. For the electron-only devices $30 \mathrm{~nm} \mathrm{ZnO}$ (according to a method published by M.T. Lloyd et al. in Ref. ${ }^{[29]}$ ) were spin coated as the bottom interface between ITO and the polymer blend and $10 \mathrm{~nm}$ Ca followed by $100 \mathrm{~nm} \mathrm{Al}$ were evaporated as the top electrode. The active area of the devices was $5 \mathrm{~mm}^{2}$.

Device characterization: Solar cells were characterized under illumination of a Steuernagel SolarConstant 1200 metal halide lamp. The intesity was set to $100 \mathrm{~mW} \mathrm{~cm}{ }^{-2}$ using a reference silicon solar cell and correcting for spectral mismatch. Photocurrent was measured on at least 5 devices per different casting solvent by using a Keithley 2400 source-measure. The EQE measurement was carried out using a lock-in amplifier (SR830, Stanford Research Systems) coupled with a monochromator and a xenon lamp under short-circuit condition.

Dark hole-only and electron-only $J-V$ curves were fitted to the following equation ${ }^{[30]}$ to extract the charge carrier mobilities:

$$
J_{e(h)}=\frac{9}{8} \text { or } r_{(h)} \exp 0.891 \quad \sqrt{\frac{V}{l}} \frac{V^{2}}{\dot{\vdots}} \frac{V^{3}}{l^{3}}
$$

where $J_{\mathrm{e}(\mathrm{h})}$ is the electron (hole) current, $\mu_{\mathrm{e}(\mathrm{h})}$ the zero-field mobility of the electrons (holes), $\gamma_{\mathrm{e}(\mathrm{h})}$ the field activation factor, $\varepsilon_{0}$ the permittivity of free space, $\varepsilon_{\mathrm{r}}$ the relative permittivity of 
the material, and 1 the thickness of the active layer. The results are the average of 6 devices for each solvent.

Bottom-gate/bottom-contact FETs were measured in vacuum and at room temperature using a Keithley 4200-SCS semiconductor parameter analyzer. Mobility was evaluated on at least 7 devices per different casting solvent in the saturation regime at a drain voltage $V_{D}= \pm 50 \mathrm{~V}$.

AFM, XPS, TEM, SEM, and GIWAXS characterization: AFM were performed using a Multimode Nanoscope IV (Digital Instruments, Santa Barbara, CA) operating in tapping mode. Etched-silicon probes with a pyramidal-shape tip having a nominal curvature of $10 \mathrm{~nm}$ and a nominal internal angle of $35^{\circ}$ were used. The AFM images were recorded with a resolution of 512 pixels $\times 512$ pixels at a tip resonance frequency of $310 \mathrm{kHz}$. XPS measurements were carried out on a PHI VersaProbe Scanning XPS Microprobe using a $\mathrm{C}_{60}$ sputter source. Although samples were processed in inert nitrogen $\left(\mathrm{N}_{2}\right)$ atmosphere, we note that nitrogen incorporation into the films is unlikely since these polymers do not chemically react with $\mathrm{N}_{2}$ and physisorbed nitrogen will be removed after insertion of the samples into the ultra-high vacuum XPS measurement chamber. Thus, any nitrogen detected in the samples arises from the $\mathrm{P}(\mathrm{NDI} 2 \mathrm{OD}-\mathrm{T} 2)$ polymer. Atomic concentrations measured by XPS are not calibrated against standards, but rather are directly proportional to the measured peak intensity and calculated from theoretically determined sensitivity factors. This allows us to make direct quantitative comparisons of atomic concentrations across samples processed from different solvents. Film thicknesses were determined using a Park Systems XE-70 AFM. TEM measurements were performed using a JEOL JEM-2100F instrument on thin films prepared under identical conditions as described before. SEM samples were mounted on copper stub with the help of carbon double-stick tape and subsequently coated with gold using a sputter coater at $3 \mathrm{~Pa}$ pressure and $30 \mathrm{~mA}$ current for 30 seconds and measured at keV beam current and $4.5 \mathrm{~mm}$ working distance. X-ray scattering was performed at the Stanford Synchrotron Radiation Lightsource (SSRL) on beam line 11-3 (2D scattering with an area detector, 
MAR345 image plate, at grazing incidence). The beam energy was $12.7 \mathrm{keV}$ and the incidence X-ray angle $\left(0.12^{\circ}\right)$ was slightly larger than the critical angle, ensuring that we sampled the full film depth. Scattering data are expressed as a function of the scattering vector $q=4 \pi^{*} \sin (\theta) / \lambda$, where $\theta$ is half the scattering angle and $\lambda$ is the wavelength of the incident radiation. Here, $q_{\mathrm{xy}}\left(q_{\mathrm{z}}\right)$ is the component of the scattering vector parallel (perpendicular) to the substrate.

\section{Supporting Information}

Supporting Information is available online from the Wiley Online Library or from the author.

\section{Acknowledgements}

M.A.L and S.F. acknowledge the expert technical support of A.F. Kamp and J. Harkema. SH gratefully acknowledges support from the National Science Foundation in the form of a graduate fellowship.

Received: ((will be filled in by the editorial staff))

Revised: ((will be filled in by the editorial staff)) Published online: ((will be filled in by the editorial staff))

\section{References}

[1] a) A. C. Arias, J. D. MacKenzie, I. McCulloch, J. Rivnay, A. Salleo, Chem. Rev. 2010, 110, 3-24; b) A. Facchetti, Materials Today 2013, 16, 123-132.

[2] a) A. C. Grimsdale, K. L. Chan, R. E. Martin, P. G. Jokisz, A. B. Holmes, Chem. Rev. 2009, 109, 897-1091; b) D. Kabra, L. P. Lu, M. H. Song, H. J. Snaith, R. H. Friend, Adv. Mater. 2010, 22, 3194-+; c) M. Al-Sa'di, F. Jaiser, S. Bagnich, T. Unger, J. Blakesley, A. Wilke, D. Neher, J. Polym. Sci. B Polym. Phys. 2012, 50, 1567-1576.

[3] a) F. Silvestri, A. Marrocchi, IJMS 2010, 11, 1471-1508; b) H. Wang, E. D. Gomez, J. Kim, Z. Guan, C. Jaye, D. A. Fischer, A. Kahn, Y.-L. Loo, Chem. Mater. 2011, 23, 2020-2023; c) S. Loser, C. J. Bruns, H. Miyauchi, R. P. Ortiz, A. Facchetti, S. I. Stupp, T. J. Marks, J. Am. Chem. Soc. 2011, 133, 8142-8145; d) T. A. M. Ferenczi, C. 
Muller, D. D. C. Bradley, P. Smith, J. Nelson, N. Stingelin, Adv. Mater. 2011, 23, 4093-+; e) N. J. Zhou, X. G. Guo, R. P. Ortiz, S. Q. Li, S. M. Zhang, R. P. H. Chang, A. Facchetti, T. J. Marks, Adv. Mater. 2012, 24, 2242-2248; f) S. Albrecht, S. Janietz, W. Schindler, J. Frisch, J. Kurpiers, J. Kniepert, S. Inal, P. Pingel, K. Fostiropoulos, N. Koch, D. Neher, J. Am. Chem. Soc. 2012, 134, 14932-14944; g) A. Marrocchi, D. Lanari, A. Facchetti, L. Vaccaro, Energ. Environ. Sci. 2012, 5, 8457-8474.

[4] a) I. McCulloch, M. Heeney, C. Bailey, K. Genevicius, I. MacDonald, M. Shkunov, D. Sparrowe, S. Tierney, R. Wagner, W. Zhang, M. L. Chabinyc, R. J. Kline, M. D. McGehee, M. F. Toney, Nature Mater. 2006, 5, 328-333; b) A. C. Arias, F. Endicott, R. A. Street, Adv. Mater. 2006, 18, 2900-+; c) Y. L. Loo, Aiche Journal 2007, 53, 1066-1074; d) H. Yan, Z. Chen, Y. Zheng, C. Newman, J. R. Quinn, F. Dötz, M. Kastler, A. Facchetti, Nature 2009, 457, 679-686; e) Z. Y. Chen, M. J. Lee, R. S. Ashraf, Y. Gu, S. Albert-Seifried, M. M. Nielsen, B. Schroeder, T. D. Anthopoulos, M. Heeney, I. McCulloch, H. Sirringhaus, Adv. Mater. 2012, 24, 647-+.

[5] a) P. Pingel, A. Zen, R. D. Abellon, F. C. Grozema, L. D. A. Siebbeles, D. Neher, Adv. Funct. Mater. 2010, 20, 2286-2295; b) A. A. Virkar, S. Mannsfeld, Z. Bao, N. Stingelin, Adv. Mater. 2010, 22, 3857-3875; c) P. Wolfer, M. L. Santarelli, L. Vaccaro, L. Y. Yu, T. D. Anthopoulos, P. Smith, N. Stingelin, A. Marrocchi, Org. Electron. 2011, 12, 1886-1892; d) S. Fabiano, H. Wang, C. Piliego, C. Jaye, D. A. Fischer, Z. H. Chen, B. Pignataro, A. Facchetti, Y. L. Loo, M. A. Loi, Adv. Funct. Mater. 2011, 21, 4479-4486.

[6] a) K. Vakhshouri, D. R. Kozub, C. C. Wang, A. Salleo, E. D. Gomez, Phys. Rev. Lett. 2012, 108, 5; b) F. C. Jamieson, E. B. Domingo, T. McCarthy-Ward, M. Heeney, N. Stingelin, J. R. Durrant, Chem. Sci. 2012, 3, 485-492.

[7] S. Fabiano, B. Pignataro, Chem. Soc. Rev. 2012, 41, 6859-6873. 
[8] a) H. Sirringhaus, P. J. Brown, R. H. Friend, M. M. Nielsen, K. Bechgaard, B. M. W. Langeveld-Voss, A. J. H. Spiering, R. A. J. Janssen, E. W. Meijer, P. Herwig, D. M. d. Leeuw, Nature 1999, 401, 685-688; b) A. Salleo, R. J. Kline, D. M. DeLongchamp, M. L. Chabinyc, Adv. Mater. 2010, 22, 3812-3838; c) S. Fabiano, C. Musumeci, Z. H. Chen, A. Scandurra, H. Wang, Y. L. Loo, A. Facchetti, B. Pignataro, Adv. Mater. 2012, 24, 951-+.

[9] C. J. Brabec, M. Heeney, I. McCulloch, J. Nelson, Chem. Soc. Rev. 2011, 40, 11851199.

[10] D. R. Barbero, U. Steiner, Phys. Rev. Lett. 2009, 102, 4.

[11] S. Walheim, M. Böltau, J. Mlynek, G. Krausch, U. Steiner, Macromolecules 1997, 30, 4995-5003.

[12] S. Y. Heriot, R. A. L. Jones, Nat. Mater. 2005, 4, 782-786.

[13] A. C. Arias, N. Corcoran, M. Banach, R. H. Friend, J. D. MacKenzie, W. T. S. Huck, Appl. Phys. Lett. 2002, 80, 1695-1697.

[14] C. Piliego, K. Szendrei, M. A. Loi, in Semiconducting Polymer Composites: Principles, Morphologies, Properties and Applications, Wiley-VCH Verlag GmbH \& Co. KGaA, 2013, pp. 457-487.

[15] S. Fabiano, Z. Chen, S. Vahedi, A. Facchetti, B. Pignataro, M. A. Loi, J. Mater. Chem. 2011, 21, 5891-5896.

[16] O. V. Mikhnenko, F. Cordella, A. B. Sieval, J. C. Hummelen, P. W. M. Blom, M. A. Loi, J. Phys. Chem. B 2009, 113, 9104-9109.

[17] C. J. Brabec, N. S. Sariciftci, J. C. Hummelen, Adv. Funct. Mater. 2001, 11, 15-26.

[18] R. Steyrleuthner, M. Schubert, I. Howard, B. Klaumunzer, K. Schilling, Z. H. Chen, P. Saalfrank, F. Laquai, A. Facchetti, D. Neher, J. Am. Chem. Soc. 2012, 134, 1830318317. 
[19] M. Schubert, D. Dolfen, J. Frisch, S. Roland, R. Steyrleuthner, B. Stiller, Z. H. Chen, U. Scherf, N. Koch, A. Facchetti, D. Neher, Adv. Energy Mater. 2012, 2, 369-380.

[20] K. Szendrei, D. Jarzab, Z. Chen, A. Facchetti, M. A. Loi, J. Mater. Chem. 2010, 20, $1317-1321$.

[21] The surface energy of P3HT and P(NDI2OD-T2) films was calculated from contact angles measured using three different known probe liquids (namely deionized water, tritoyl phosphate and glycerol), as suggested by Good, R. J.; Chaudhury, M. K.; van Oss, C. J. Fundamentals of Adhesion; Plenum Press: New York, 1991; p 1153.

[22] S. C. Lim, S. H. Kim, J. H. Lee, M. K. Kim, D. J. Kim, T. Zyung, Synth. Met. 2005, 148, 75-79.

[23] S. Goffri, C. Muller, N. Stingelin-Stutzmann, D. W. Breiby, C. P. Radano, J. W. Andreasen, R. Thompson, R. A. J. Janssen, M. M. Nielsen, P. Smith, H. Sirringhaus, Nature Mater. 2006, 5, 950-956.

[24] M. Mas-Torrent, D. d. Boer, M. Durkut, P. Hadley, A. P. H. J. Schenning, Nanotechnology 2004, 15, S265-S269.

[25] X. J. Wang, T. Ederth, O. Inganas, Langmuir 2006, 22, 9287-9294.

[26] J. Rivnay, M. F. Toney, Y. Zheng, I. V. Kauvar, Z. Chen, V. Wagner, A. Facchetti, A. Salleo, Adv. Mater. 2010, 22, 4359-4363.

[27] a) Y. Kim, S. Cook, S. A. Choulis, J. Nelson, J. R. Durrant, D. D. C. Bradley, Chem. Mater. 2004, 16, 4812-4818; b) T. Kietzke, H.-H. Hörhold, D. Neher, Chem. Mater. 2005, 17, 6532-6537; c) M. P. Felicissimo, D. Jarzab, M. Gorgoi, M. Forster, U. Scherf, M. C. Scharber, S. Svensson, P. Rudolf, M. A. Loi, J. Mater. Chem. 2009, 19, 4899-4901.

[28] a) E. J. Meijer, D. M. d. Leeuw, S. Setayesh, E. v. Veenendaal, B.-H. Huisman, P. W. M. Blom, J. C. Hummelen, U. Scherf, T. M. Klapwijk, Nature Mater. 2003, 2, 678682; b) D. K. Hwang, C. Fuentes-Hernandez, J. Kim, W. J. Potscavage, S. J. Kim, B. 
Kippelen, Adv. Mater. 2011, 23, 1293-+; c) C. Rost, S. Karg, W. Riess, M. A. Loi, M. Murgia, M. Muccini, Appl. Phys. Lett. 2004, 85, 1613-1615; d) M. A. Loi, C. RostBietsch, M. Murgia, S. Karg, W. Riess, M. Muccini, Adv. Funct. Mater. 2006, 16, 4147.

[29] M. T. Lloyd, C. H. Peters, A. Garcia, I. V. Kauvar, J. J. Berry, M. O. Reese, M. D. McGehee, D. S. Ginley, D. C. Olson, Sol. Energy Mater. Sol. Cells 2011, 95, 13821388.

[30] V. D. Mihailetchi, H. X. Xie, B. de Boer, L. J. A. Koster, P. W. M. Blom, Adv. Funct. Mater. 2006, 16, 699-708. 


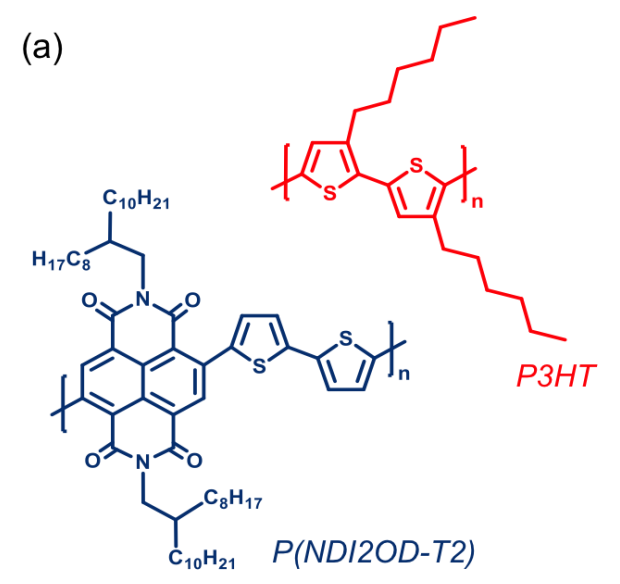

(b)

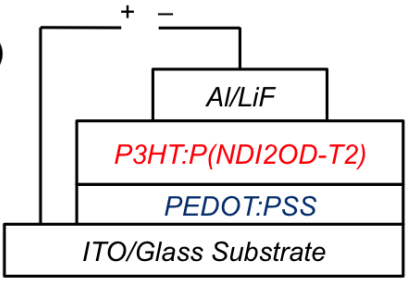

(d)

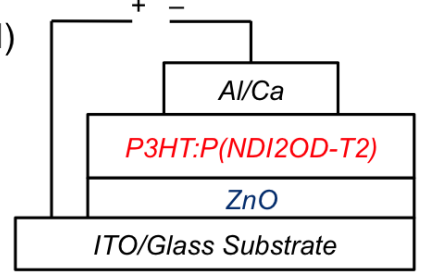

(c)

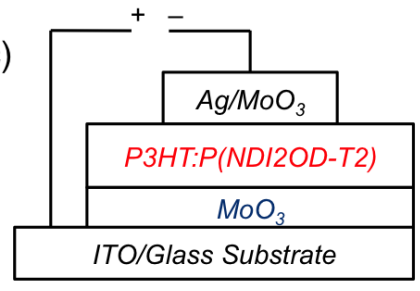

(e)

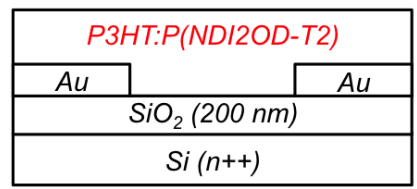

Figure 1. Chemical structures of P3HT and P(NDI2OD-T2) (a). Schematic representation of the four types of devices used in this work: (b) PSC, (c) hole-only device, (d) electron-only device and (e) bottom-gate/bottom-contact FET. 

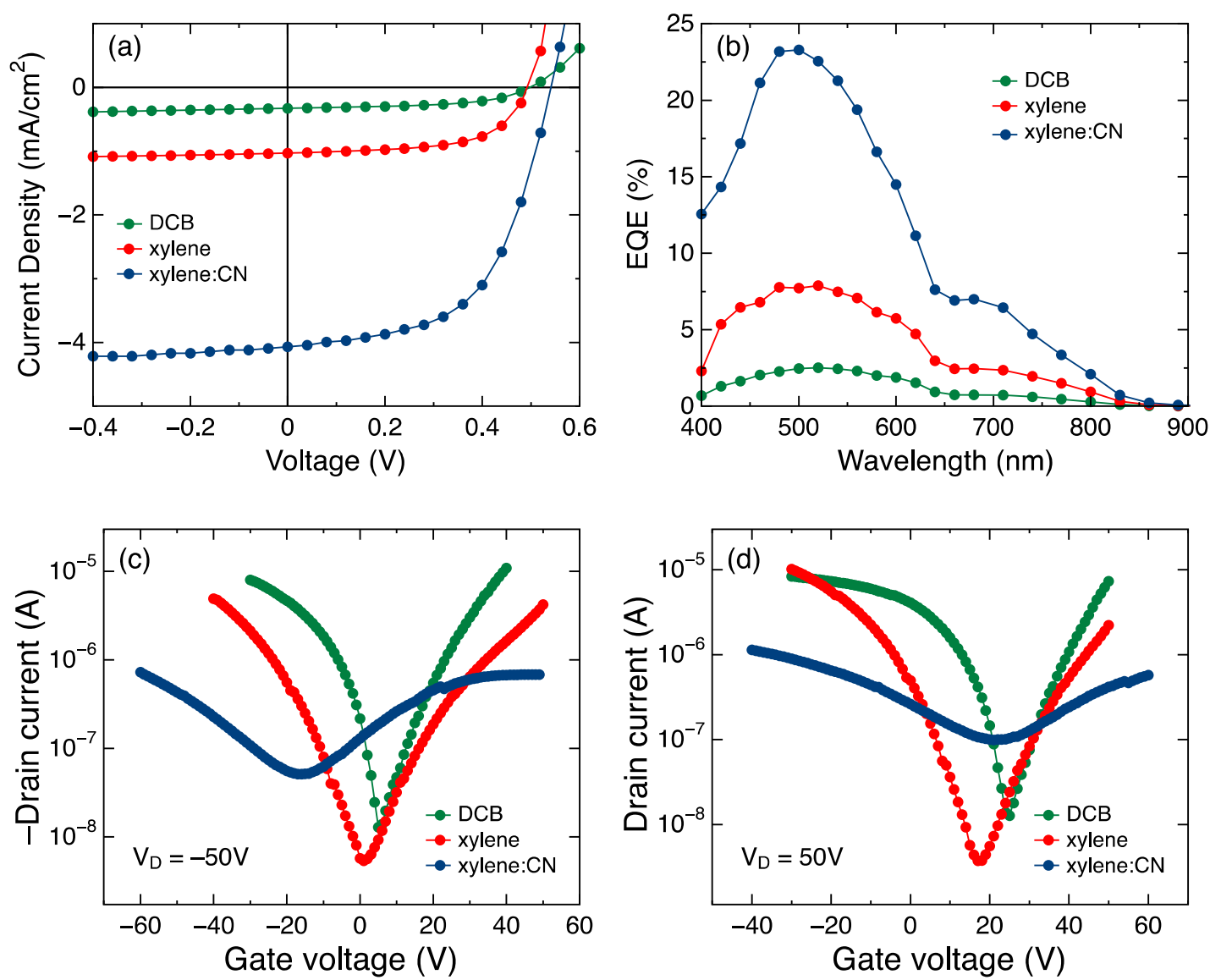

Figure 2. Representative $J-V$ characteristics (a) and EQE spectra (b) of P3HT:P(NDI2OD-T2) BHJ solar cells spin-coated from different solvents: DCB (green), xylene (red) and xylene:CN (blue). (c,d) Transfer characteristics of P3HT:P(NDI2OD-T2) field-effect transistors prepared from different solvents (channel widths of $10 \mathrm{~mm}$ and lengths of $20 \mu \mathrm{m}$ ), for both p-channel (c) and n-channel $(\mathrm{d})$ operation $\left(\mathrm{V}_{\mathrm{D}}= \pm 50 \mathrm{~V}\right)$. 

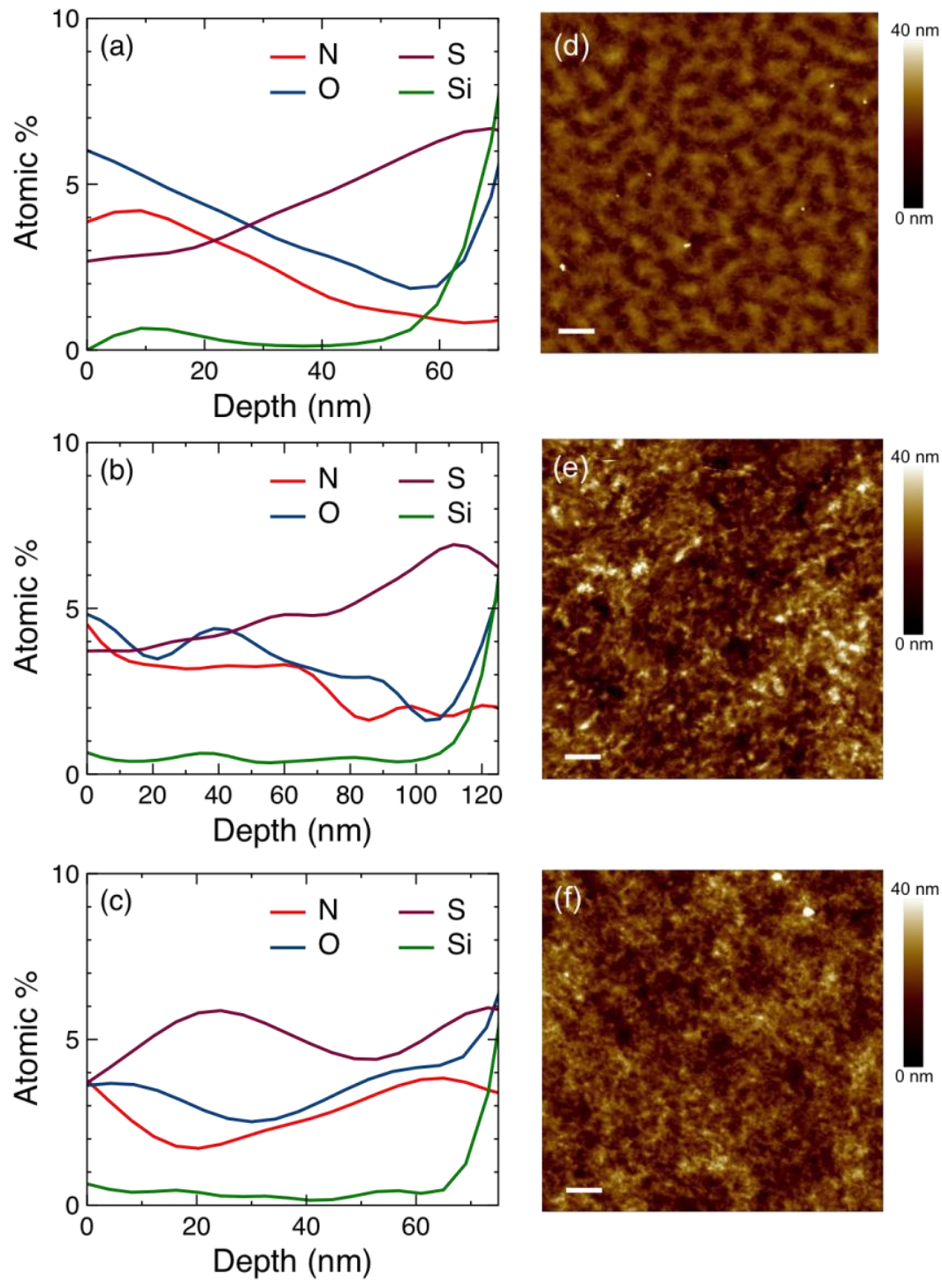

Figure 3. XPS depth profiles showing elemental distribution for P3HT (C, S) / P(NDI2ODT2) (C, N, O, S) blends spin-coated from DCB (a), xylene (b) and xylene:CN (c) and of the substrate $(\mathrm{Si})$. Atomic force microscopy images of the corresponding P3HT:P(NDI2OD-T2) films spin-coated from either DCB (d), xylene (e) and xylene:CN (f). The scale bar is $1 \mu \mathrm{m}$. 


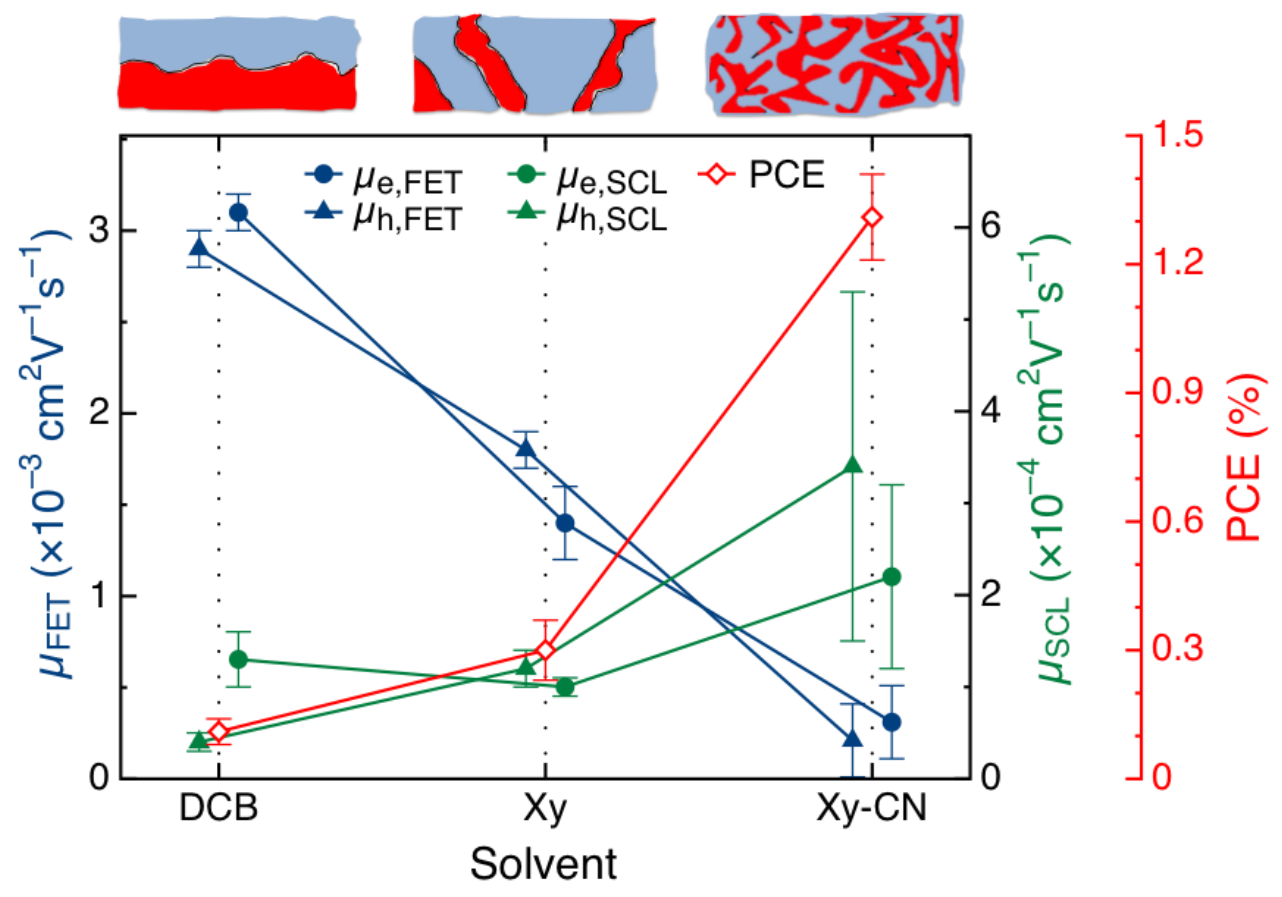

Figure 4. Solvent effect with schematic representation of the blend morphology (top) on the PCE and ambipolar mobility of P3HT:P(NDI2OD-T2) blends. The large SCL mobility range provided for the blends cast from xylene: $\mathrm{CN}$ is due to the large film thickness variations. 
Table 1. Photovoltaic and transport parameters for P3HT:P(NDI2OD-T2) BHJ solar cells, diodes, and FETs processed by different solvents.

\begin{tabular}{|c|c|c|c|c|c|c|c|c|}
\hline \multirow[b]{2}{*}{ Solvent } & \multirow{2}{*}{$\begin{array}{c}J_{\mathrm{sc}} \\
{\left[\mathrm{mAcm}^{-2}\right]}\end{array}$} & \multirow{2}{*}{$\begin{array}{l}\mathrm{V}_{\mathrm{oc}} \\
{[\mathrm{V}]}\end{array}$} & \multirow{2}{*}{$\begin{array}{l}\mathrm{FF} \\
{[\%]}\end{array}$} & \multirow{2}{*}{$\begin{array}{l}\text { PCE } \\
{[\%]}\end{array}$} & \multicolumn{2}{|c|}{ FET Mobility } & \multicolumn{2}{|c|}{ SCL Mobility } \\
\hline & & & & & $\begin{array}{c}\mu_{\mathrm{e}^{\mathrm{a}}} \\
{\left[\mathrm{cm}^{2} \mathrm{~V}^{-1} \mathrm{~s}^{-1}\right]}\end{array}$ & $\begin{array}{c}\mu_{\mathrm{h}^{\mathrm{a}}} \\
{\left[\mathrm{cm}^{2} \mathrm{~V}^{-1} \mathrm{~s}^{-1}\right]}\end{array}$ & $\begin{array}{c}\mu_{\mathrm{e}} \\
{\left[\mathrm{cm}^{2} \mathrm{~V}^{-1} \mathrm{~s}^{-1}\right]}\end{array}$ & $\begin{array}{c}\mu_{\mathrm{h}} \\
{\left[\mathrm{cm}^{2} \mathrm{~V}^{-1} \mathrm{~s}^{-1}\right]}\end{array}$ \\
\hline DCB & $0.30 \pm 0.05$ & $0.49 \pm 0.02$ & $56 \pm 2$ & $0.11 \pm 0.03$ & $3.1 \pm 0.1 \times 10^{-3}$ & $2.9 \pm 0.1 \times 10^{-3}$ & $1.3 \pm 0.3 \times 10^{-4}$ & $0.4 \pm 0.1 \times 10^{-4}$ \\
\hline Xylene & $1.02 \pm 0.10$ & $0.50 \pm 0.01$ & $58 \pm 3$ & $0.30 \pm 0.07$ & $1.4 \pm 0.2 \times 10^{-3}$ & $1.8 \pm 0.1 \times 10^{-3}$ & $1.0 \pm 0.1 \times 10^{-4}$ & $1.2 \pm 0.2 \times 10^{-4}$ \\
\hline Xylene:CN & $4.18 \pm 0.21$ & $0.53 \pm 0.02$ & $59 \pm 3$ & $1.31 \pm 0.10$ & $3.1 \pm 0.2 \times 10^{-4}$ & $2.1 \pm 0.2 \times 10^{-4}$ & $2.2 \pm 1.0 \times 10^{-4 b}$ & $3.4 \pm 1.9 \times 10^{-4 b}$ \\
\hline
\end{tabular}

a) The FET mobilities were calculated in the saturation regime $\left(\mathrm{V}_{\mathrm{D}}= \pm 50 \mathrm{~V}\right) .{ }^{\text {b) }}$ The large standard deviation is due to the large film thickness variations. 
Polymer aggregation and phase separation of a polymer-polymer blend are effectively tuned from self-stratified to laterally phase-separated by adjusting the relative solubility of the two polymers in the mixture. This is found to alter dramatically the charge transport characteristics from a preferential in-plane to an out-of-plane direction, revealing a critical dependence of the resulting device performances on the film morphology and structure of the active layers.

Keyword Charge Transport

Simone Fabiano, Scott Himmelberger, Martin Drees, Zhihua Chen, Rashid M. Altamimi, Alberto Salleo,* Maria Antonietta Loi,* and Antonio Facchetti*

Charge Transport Orthogonality in All-Polymer Blend Transistors, Diodes, and Solar Cells

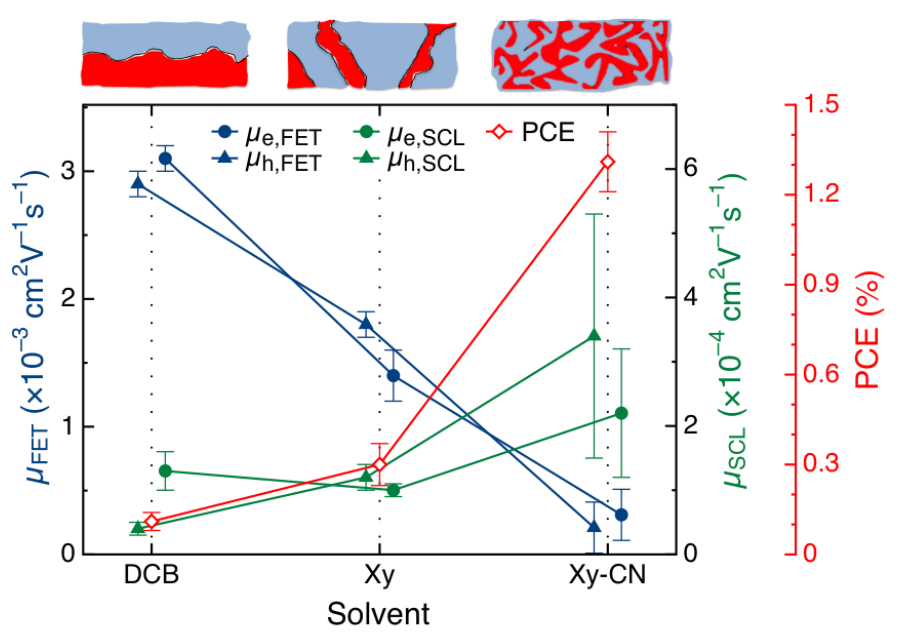

